\title{
A New Set-Up to Investigate Plastic Deformation of Face Centered Cubic Metals in High Strain Rate Loading
}

\author{
Ehsan Etemadi ${ }^{1}$, Jamal Zamani ${ }^{1}$, Alessandro Francesconi ${ }^{2}$, Mohammad V. Mousavi ${ }^{1}$ \& Cinzia Giacomuzzo ${ }^{2}$ \\ ${ }^{1}$ Department of Mechanical Engineering, K.N. Toosi University of Technology, Tehran, Iran \\ ${ }^{2}$ Department of Industrial Engineering, University of Padova, Italy \\ Correspondence: Ehsan Etemadi, Modern Metal Forming Laboratory, Department of Mechanical Engineering, \\ K.N. Toosi University of Technology, No. 19, Pardis St., Mollasadra St., Tehran, P.O. Box 19395-1999, Iran. \\ E-mail: ehsanetemadi@yahoo.com
}

Received: November 28, 2013

Accepted: January 15, $2014 \quad$ Online Published: March 11, 2014

doi:10.5539/mas.v8n2p94

URL: http://dx.doi.org/10.5539/mas.v8n2p94

\begin{abstract}
This paper presents a novel set-up designed to investigate plastic deformation of a metal at high strain rates. The set-up is similar to conventional split Hopkinson pressure bar but the striker bar is eliminated and instead of it a spherical projectile, accelerated to high velocity with a two-stage light-gas gun, impacts and penetrates in a steel plate attached to the input bar. This results in propagation of plane waves in the bars and the sample. Impacts were carried out by aluminum spherical projectiles with diameter of $3.5 \mathrm{~mm}$ and velocity between 2 and 2.5 $\mathrm{km} / \mathrm{s}$ onto front plates with thickness $10 \mathrm{~mm}$ and diameter of $55 \mathrm{~mm}$; the thickness of samples was between 3 and $7 \mathrm{~mm}$. The experimental results were compared with 3D finite element simulation. Also, the effect of projectile velocity and sample thickness were investigated through experimental tests.
\end{abstract}

Keywords: plastic deformation, high velocity impact, finite element method, wave propagation, split Hopkinson pressure bar

\section{Introduction}

Constitutive equations associate flow stress to effective parameters such as strain, strain rate and temperature (Meyers, 1994). Flow stress in metals logarithmically increases in the ranges of less than $10^{3} \mathrm{~s}^{-1}$ or $10^{4} \mathrm{~s}^{-1}$ (dependent on the material) however for the strain rate larger than $10^{3} \mathrm{~s}^{-1}$ or $10^{4} \mathrm{~s}^{-1}$, flow stress goes up much more dramatically. Follansbee and Kocks (1998) and Follansbee and Gray (1991) demonstrated that the flow stress in OFHC copper starts to rise from the strain rate of $10^{3} \mathrm{~s}^{-1}$.

Many experimental works were conducted to obtain constitutive relations of different materials at high strain rates. Field, Walley, Proud, Goldrein and Siviour (2004) reviewed different experimental methods to investigate high strain rate loadings. Experiments at high strain rates for different materials were performed using the split Hopkinson bar (Sasso, Newaz, \& Amodio, 2008), Taylor impact (Liu, Tan, Zhang, Hu, Ma, Wang, \& Cai, 2009), plate impact experiment (Frutschy \& Clifton, 1998), and high intensity laser (Ren, Zhan, Yang, Dai, Cui, Sun, \& Ruan, 2013).

In particular, split Hopkinson bar is used to evaluate dynamic properties of metals in compression (Zou, Luan, Liu, Chai, \& Chen, 2012; Yang, Tang, Y. Liu, Z. Liu, Jiang, \& Fang, 2013), tension (Gerlach, Kettenbeil, \& Petrinic, 2012), and torsion (Gilat \& Cheng, 2002), with strain rates between $10^{2}$ and $10^{4} \mathrm{~s}^{-1}$ (Gray, 2000), and for different FCC metals such as OFHC copper (Follansbee \& Kocks, 1988; Wang \& Meyer, 2010; Kapoor \& Nemat-Nasser, 1998), Aluminum (Yang et al., 2013; Kapoor \& Nemat-Nasser, 1998), and any other kind of metals such as steel (Sedighi, Khandaei, \& Shokrollahi, 2010; Kajberg \& Sundin, 2013). Many works have been done on this subject from an experimental as well as numerical point of view.

In the usual split Hopkinson pressure bar (SHPB) system, a sample is placed between two elastic pressure bars (input and output bar), made of high strength material, so that they remain elastic even though the sample itself may be taken to plastic strains. SHPB test is based on two assumptions: on one hand, force is in equilibrium on both sides of the sample. The required time and number of wave transits in the sample to satisfy this assumption depends on the sample length, relative impedance and sample to bars area (Ravichandran \& Subhash, 1994; Yang \& Shim, 2005). On the other hand, the sample deforms at constant volume. 
Dynamic loading can be produced in SHPB by different ways. The regular method is to impact one end of the striker bar on the input bar. The impact of a striker bar on the input bar propagates a longitudinal compressive incident wave in input bar. Once this wave gets to the bar-sample interface, a part of the wave is reflected while the remainder of the wave propagates through the sample and is transmitted to the output bar (Field et al., 2004).

Where $\varepsilon_{t}$ is the strain pulse measured in the output bar (transmitted pulse), $\varepsilon_{r}$ is the strain pulse reflected from the sample and $\varepsilon_{i}$ is the incident strain pulse measured in the input bar.

The incident, reflected, and transmitted waves are recorded with strain gauges, often mounted on the center of input and output bars.

Numerical analysis such as finite element method (FEM) along with experimental methods is extensively used to simulate the behaviour of different materials under split Hopkinson bar experiments. Simulations were carried out with different commercial software such as Abaqus (Liu \& Sun, 2014; Li \& Ramesh, 2007; Verleysen \& Degrieck, 2006), Ansys (Sedighi, Khandaei, \& Shokrollahi, 2010; Khosravifard, Moshksar, \& Ebrahimi, 2013), and LS-Dyna (Qin, Chen, Wen, Lin, Liang, \& Lu, 2013; Kajberg \& Wikman, 2007; Clausen, Børvik, Hopperstad, $\&$ Benallal, 2004). The constitutive models to describe plastic behaviour of materials with FEM include plastic models such as Johnson-Cook (Liu \& Sun, 2014; Qin, Chen, Wen, Lin, Liang, \& Lu, 2013; Kajberg \& Wikman, 2007) and Power law (Li \& Ramesh, 2007; Khosravifard, Moshksar, \& Ebrahimi, 2013).

Starting from this background, this paper describes a new set-up to investigate plastic response of OFHC copper at high strain rate loadings. The set-up is similar to conventional SHPB but the striker bar is eliminated. Instead of it, a high-velocity spherical projectile impacts a steel plate attached to the front of the input bar and results in propagation of plane waves in the bars and the sample. Experimental results were compared with 3D finite element simulations. Also, the effect of projectile velocity, sample thickness and front plate thickness were investigated in order to achieve larger strain rates.

\section{Experimental Set up}

The test apparatus consisted of a two stage light gas gun to launch high-speed spherical projectiles, and the target assembly. Figure 1 and Figure 2 show a sketch and two pictures of the target assembly, that includes a front plate, the input and output bars, three frames, a sample, and a rigid holder. Table 1 reports materials and size of spherical projectile, front plate, pressure bars and the sample. The sample is OFHC copper and the bars and front plates are from steel 4340. Also flyer is from aluminum 1100.

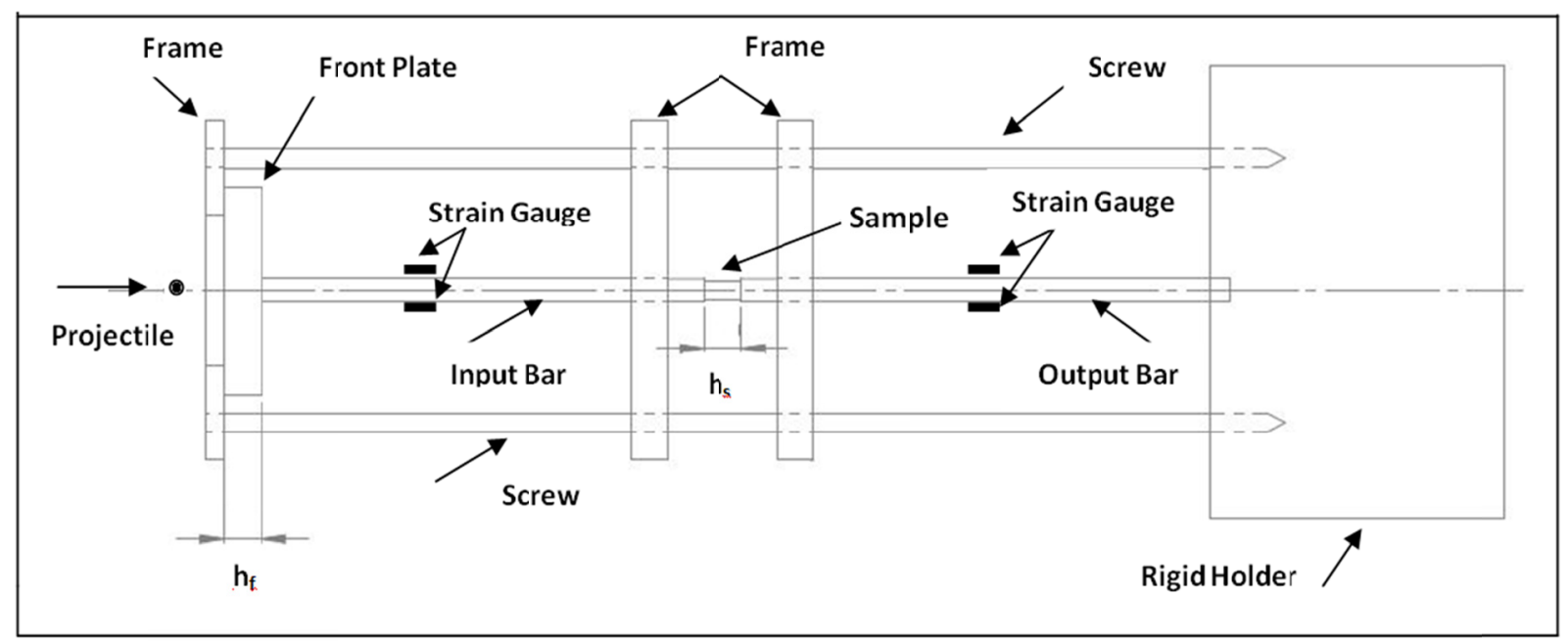

Figure 1. Target assembly schematic 


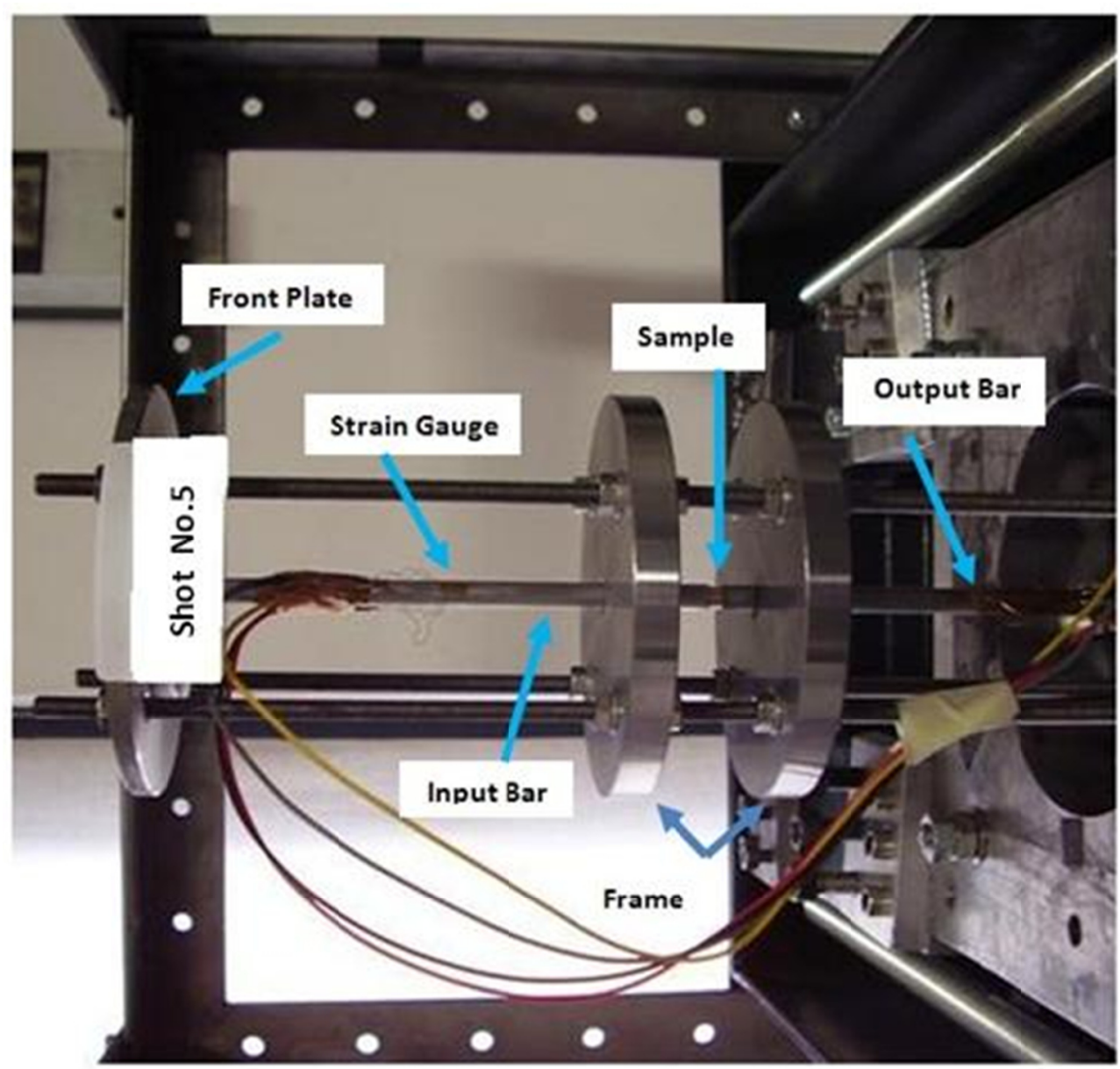

(a)

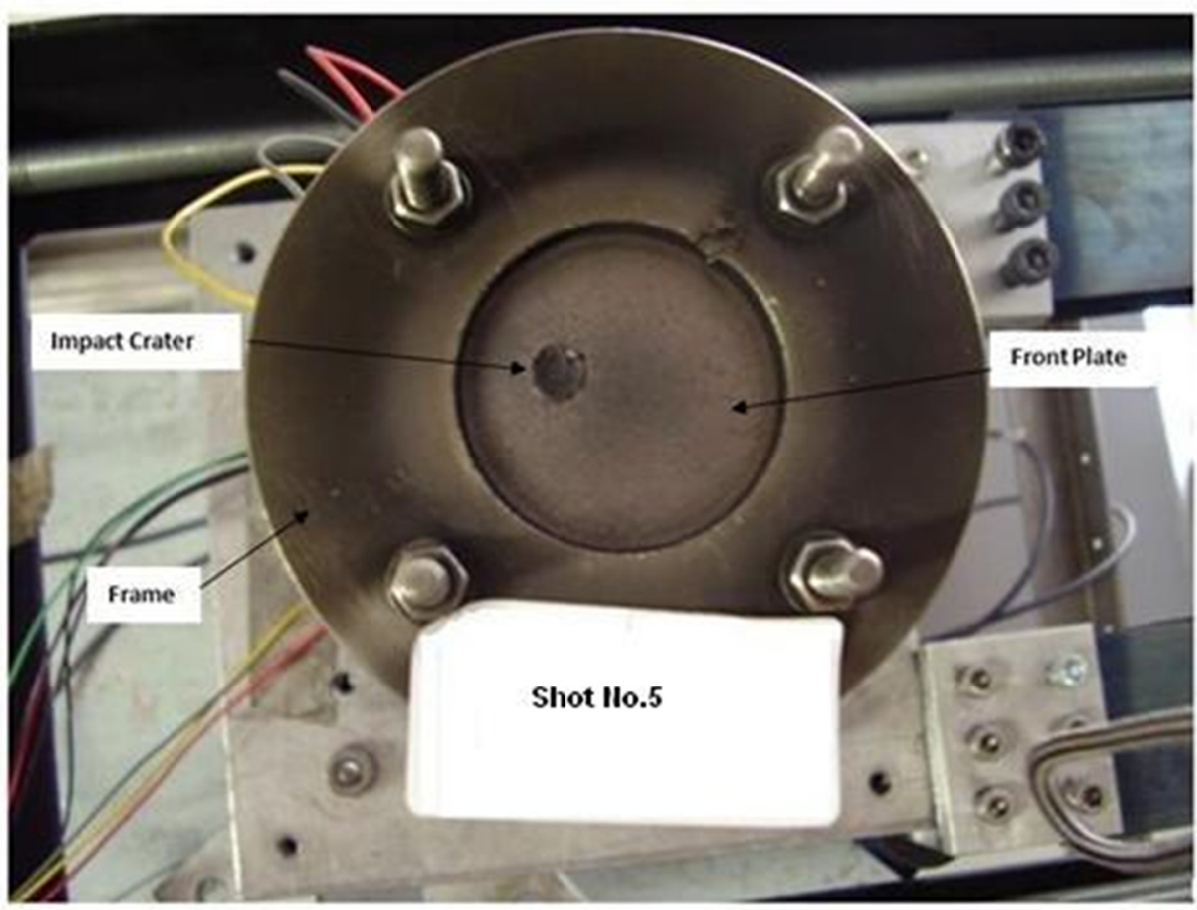

(b)

Figure 2. (a) Target assembly (b) front plate after impact 
Table 1. Materials and size of spherical projectile, front plate, pressure bars and specimen

\begin{tabular}{ccccccc}
\hline & Material & $\begin{array}{c}\text { Young modulus, } \\
\mathrm{E}(\mathrm{GPa})\end{array}$ & $\begin{array}{c}\text { Density, } \rho \\
\left(\mathrm{kg} / \mathrm{m}^{3}\right)\end{array}$ & $\begin{array}{c}\text { Poisson } \\
\text { ratio, } v\end{array}$ & $\begin{array}{c}\text { Length (thickness) } \\
(\mathrm{mm})\end{array}$ & $\begin{array}{c}\text { Diameter } \\
(\mathrm{mm})\end{array}$ \\
\hline Specimen & $\begin{array}{c}\text { OFHC } \\
\text { copper }\end{array}$ & 129.8 & 8960 & 0.34 & $3-10$ & 5 \\
$\begin{array}{c}\text { Input and } \\
\text { Output bars }\end{array}$ & Steel 4340 & 200 & 7830 & 0.29 & 120 & 6 \\
$\begin{array}{c}\text { Front Plate } \\
\text { Spherical } \\
\text { Projectile }\end{array}$ & Steel 4340 & 200 & 7830 & 0.29 & 10 & 55 \\
\hline
\end{tabular}

Impact experiments were carried out at the CISAS Hypervelocity Impact Facility that is based upon a two-stage light as gun (Angrilli, Pavarin, De Cecco, \& Francesconi, 2003; Pavarin \& Francesconi, 2004; Francesconi, Pavarin, Bettella, \& Angrilli, 2008) with the ability to accelerate projectiles up to $100 \mathrm{mg}$ at a maximum speed of $6 \mathrm{~km} / \mathrm{s}$. The impact facility has been used in the past to investigate the impact behavior of various materials for different structures at different impact conditions (Colombo, Arcaro, Francesconi, Pavarin, Rondini, \& Debei, 2003; Nagao, Kibe, Daigo, Francesconi, \& Pavarin, 2005; Francesconi, Pavarin, Giacomuzzo, \& Angrilli, 2006; Francesconi et al., 2008; Pavarin et al., 2008; Higeshide, Nagao, KIbe, Francesconi, \& Pavarin, 2009; Francesconi, Giacomuzzo, Kibe, Nagao, \& Higashide, 2012; Francesconi, 2013; Francesconi, Giacomuzzo, Barilaro, Segato, \& Sansone, 2013; Francesconi, Giacomuzzo, Branz, \& Lorenzini, 2013). For this study, 3.5 $\mathrm{mm}$ spherical projectiles were launched at velocities in the ranges of 2 to $2.5 \mathrm{~km} / \mathrm{s}$. The impact angle was $0^{\circ}$ for all the tests. In each experiment, an aluminum projectile was launched onto the front plate creating a crater on it and producing pressure waves that were transmitted to the input bar. In order to obtain plane waves in the bar, the front plate thickness, the input bar diameter and the impact velocity were selected according to the results of the numerical simulations presented later in section 3.2.

Strain gauges SR4 VISHAY MICRO-MEASUREMENT with a gage length of $3 \mathrm{~mm}$ and gage factor of 2.08 were used on pressure bars. The signals from the strain gauges on the input and output bars were amplified with two 2310 Vishay amplifiers with $100 \mathrm{kHz}$ bandwidth. The output signals were acquired by an oscilloscope with sampling rate equal to $250 \mathrm{MS} / \mathrm{s}$. For each test, stress $(\sigma)$, strain rate $(\dot{\varepsilon})$ and strain $(\varepsilon)$ in the sample were calculated using the following equations (Field et al., 2004):

$$
\begin{gathered}
\sigma(t)=\frac{A E \varepsilon_{t}}{A_{s}} \\
\dot{\varepsilon}=\frac{2 c_{b} \varepsilon_{r}}{h_{s}} \\
\varepsilon=\int \dot{\varepsilon} d t
\end{gathered}
$$

Where $\mathrm{E}$ is the Young's modulus of the bar material, $c_{b}$ is the elastic wave speed in the bar material which is $5850 \mathrm{~m} / \mathrm{s}$ for steel 4340 and $h_{s}$ is the sample thickness. Table 2 summarizes the test parameters for different projectile velocities $(V)$, front plate thickness $\left(h_{f}\right)$, sample thicknesses $\left(h_{s}\right)$, penetration depth $\left(d_{h}\right)$.

Table 2. Test parameters. Uncertainly are $\pm 50 \mathrm{~m} / \mathrm{s}$ for $\mathrm{V}, \pm 0.05 \mathrm{~mm}$ for $\mathrm{h}_{\mathrm{f}}, \mathrm{h}_{\mathrm{s}}$ and $\mathrm{d}_{\mathrm{h}}$

\begin{tabular}{ccccc}
\hline Shot No. & $\mathrm{V}(\mathrm{km} / \mathrm{s})$ & $\mathrm{h}_{\mathrm{f}}(\mathrm{mm})$ & $\mathrm{h}_{\mathrm{s}}(\mathrm{mm})$ & $\mathrm{d}_{\mathrm{h}}(\mathrm{mm})$ \\
\hline 1 & 2.00 & 10.00 & 3.00 & 1.10 \\
2 & 2.20 & 10.00 & 3.00 & 1.15 \\
3 & 2.00 & 10.00 & 5.00 & 1.10 \\
4 & 2.00 & 10.00 & 7.00 & 1.15 \\
5 & 2.40 & 10.00 & 3.00 & 1.20 \\
6 & 2.50 & 10.00 & 3.00 & 1.25 \\
\hline
\end{tabular}




\section{Finite Element Simulations}

\subsection{Modeling of Problem}

The experimental tests described in section 2 were reproduced with Abaqus 3D. Abaqus is standard and successful software to simulate plastic deformation of FCC metals in high strain rate loadings (Liu \& Sun, 2014; Li \& Ramesh, 2007; Verleysen \& Degrieck, 2006).

An elastic model was used for modeling input and output bars made of steel 4340. Johnson-Cook plasticity model (Johnson \& Cook, 1983) was used for modeling plastic deformation of projectile, front plate and sample. Foresaid constitutive model has much success because of its simplicity and the availability of parameters for various materials of interest (Khan \& Liang, 1999; Armstrong \& Walley, 2008). The Johnson-Cook plasticity model is:

$$
\sigma=\left(A+B \varepsilon^{n}\right)\left(1+C \ln \frac{\dot{\varepsilon}}{\dot{\varepsilon}_{0}}\right)\left[1-\left(\frac{T-T_{r}}{T_{m}-T_{r}}\right)^{m}\right]
$$

where $A$ is the static strength, $B$ the strain-hardening modulus, $\varepsilon$ the normal strain, $C$ the rate sensitivity coefficient, $m$ the thermal-softening exponent, $n$ the strain-hardening exponent, $\dot{\varepsilon}$ the strain rate, $\dot{\varepsilon}_{0}$ the reference strain rate, $\varepsilon$ the normal strain, $T$ the current temperature, $T_{0}$ the room temperature, and $T_{m}$ the melting temperature. Table 3 reports the mechanical properties of steel 4340, Al 1100 and OFHC copper as well as the coefficients of Johnson-Cook plasticity model for OFHC copper (Johnson \& Cook, 1983; Khan \& Liang, 1999; Armstrong \& Walley, 2008; Fathipour, Zoghipour, Tarighi, \& Yousefi, 2012).

Table 3. Coefficients in the Johnson-Cook plasticity model (Johnson \& Cook, 1983; Khan \& Liang, 1999; Armstrong \& Walley, 2008), Johnson-Cook damage model (Fathipour, Zoghipour, Tarighi, \& Yousefi, 2012; Johnson \& Cook, 1985) and Mie-Gruneisen EOS for different metals (Corbett, 2006; Steinberg, 1996)

\begin{tabular}{cccccccccccccccc}
\hline & $\mathrm{A}(\mathrm{MPa})$ & $\begin{array}{c}\mathrm{B} \\
(\mathrm{MPa})\end{array}$ & $\mathrm{n}$ & $\mathrm{C}$ & $\mathrm{m}$ & $\begin{array}{c}\dot{\varepsilon}_{0} \\
\left(\mathrm{~s}^{-1}\right)\end{array}$ & $\mathrm{T}_{\mathrm{m}}(\mathrm{K})$ & $\mathrm{D}_{1}$ & $\mathrm{D}_{2}$ & $\mathrm{D}_{3}$ & $\mathrm{D}_{4}$ & $\mathrm{D}_{5}$ & $\begin{array}{c}\mathrm{c}_{0} \\
(\mathrm{~m} / \mathrm{s})\end{array}$ & $\mathrm{S}_{\alpha}$ & $\Gamma_{0}$ \\
\hline OFHC copper & 90 & 292 & 0.31 & 0.025 & 1.09 & 1 & 1356 & - & - & - & - & - & - & - & - \\
Al 1100 & 148 & 361 & 0.184 & 0.001 & 0.859 & 1 & 1220 & 0.071 & 1.248 & -1.14 & 0.147 & 0.1 & 3935 & 1.578 & 1.69 \\
Steel 4340 & 792 & 510 & 0.26 & 0.014 & 1.03 & 1 & 1793 & 0.05 & 3.44 & -2.12 & 0.002 & 0.61 & 5386 & 1.337 & 1.97 \\
\hline
\end{tabular}

In addition to the plasticity model, the Johnson-Cook damage model was used to simulate failure in both of front plate and projectile. This model is appropriate to predict initiation of damage in ductile materials experiencing large pressures, strain rates and temperatures (Johnson \& Cook, 1985). The model is:

$$
\begin{gathered}
D=\sum \frac{\Delta \varepsilon_{p}}{\varepsilon_{f}} \\
\varepsilon_{\mathrm{f}}=\left[\mathrm{D}_{1}+\mathrm{D}_{2} \exp \left(\mathrm{D}_{3} \sigma^{*}\right)\right]\left[1+\mathrm{D}_{4} \ln \left(\frac{\dot{\varepsilon_{p}}}{\dot{\varepsilon_{0}}}\right)\right]\left[1+D_{5} T^{*}\right]
\end{gathered}
$$

Coefficients of $\mathrm{D}_{1}$ to $\mathrm{D}_{5}$ are reported in Table 3 (Fathipour, Zoghipour, Tarighi, \& Yousefi, 2012; Johnson \& Cook, 1985). $\mathrm{D}$ is the damage parameter and failure occurs when $\mathrm{D}=1 . \sigma^{*}$ is stress triaxiality and is defined as ratio of effective to hydrostatic stress. $\mathrm{D}_{1}$ to $\mathrm{D}_{5}$ are material-dependent parameters. Johnson-Cook damage model was used for simulation of projectile penetration to the front target. An element removes from the mesh when damage parameter (D) reaches the ultimate value.

The Mie- Grüneisen EOS was used to describe the volumetric behavior of Al 1100 and steel 4340:

$$
p=p_{H}+\Gamma_{0} \rho_{0}\left(e-\mathrm{e}_{\mathrm{H}}\right)
$$

Where $p$ is hydrostatic pressure, $\rho_{0}$ is the initial density, $\Gamma_{0}$ is the Gruneisen's gamma at reference state, $p_{H}$ and $\mathrm{e}_{\mathrm{H}}$ are:

$$
p_{H}=\frac{\rho_{0} c_{0}^{2} \eta(1+\eta)}{1-\left(1-\mathrm{S}_{\mathrm{a}}\right) \eta^{2}}
$$




$$
\mathrm{e}_{\mathrm{H}}=0.5\left(\frac{p_{H}}{\rho_{0}}\right)\left(\frac{\eta}{1+\eta}\right)
$$

Where $\mathrm{c}_{0}$ is the bulk speed of sound in the material, $\mathrm{S}_{\mathrm{a}}$ is the linear Hugoniot slope coefficient and $\eta$ is:

$$
\eta=1-\frac{\rho_{0}}{\rho}
$$

Where $\rho$ is the current density. $\Gamma_{0}$ is the Gruneisen's gamma at reference state, $\mathrm{c}_{0}, \mathrm{~S}_{\mathrm{a}}$ and $\Gamma_{0}$ are material parameters presented in Table 3 for Al 1100 and steel 4340 (Corbett, 2006; Steinberg, 1996).

The FE model employed C3D8R elements - solid, linear, 3-Dimensional, with 8 nodes. The minimum element size in the sample, front plate, bars and projectile were of order $0.25 \mathrm{~mm}, 0.50 \mathrm{~mm}, 0.50 \mathrm{~mm}$ and $0.30 \mathrm{~mm}$, respectively. There were all together 188107 elements in the whole set up.

To simulate the contact between the projectile and the front plate, general contact with friction coefficient equal to 0.1 was used. To simulate the contact between other parts, surface to surface contact was used. Considering the boundary conditions, the bars were prevented from movement and rotation except in the wave propagation direction. The explicit method is implemented to solve the problem. Figure 3 shows a section of target assembly with FE simulation.

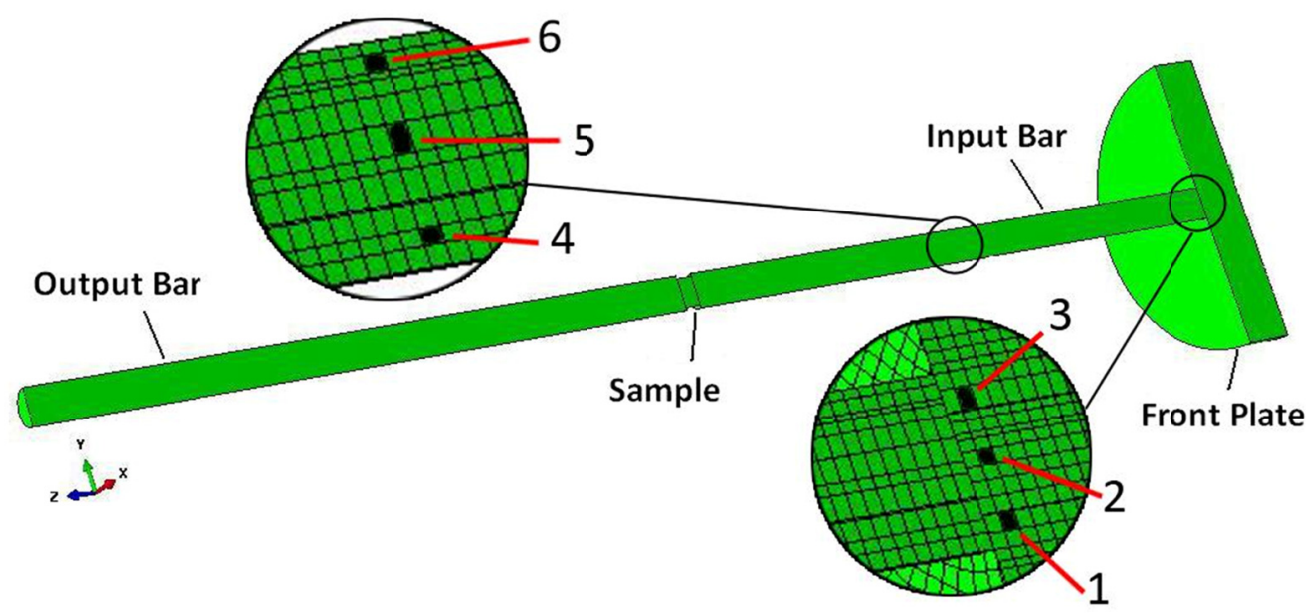

Figure 3. FE modeling of target assembly including chosen elements for front plate and input bar (Elements 1, 2 and 3 for front plate and Elements 4, 5 and 6 for input bar

\subsection{Propagation of Plane Waves in Input Bar}

Numerical simulations were used to verify if the waves propagating into the input bars can be considered planar with good approximation. The stress histories were compared in two sections on the front plate close to intersection of front plate and input bar (Elements 1,2,3) and on the input bar, close to the strain gauges position (Element 4, 5, 6). Figure 3 shows chosen elements in front plate and input bar. Results are presented in Figure 4 for shot No.5. Since the selected elements are aligned along the sections diameter and the difference of the stress profiles is always less than $5 \%$ on these elements, it was concluded that plane waves propagate in the input bar. The pressure stress propagated in the bars for all of the shots are less than yield stress of the bars. Therefore the bars were under elastic deformation during shots. 


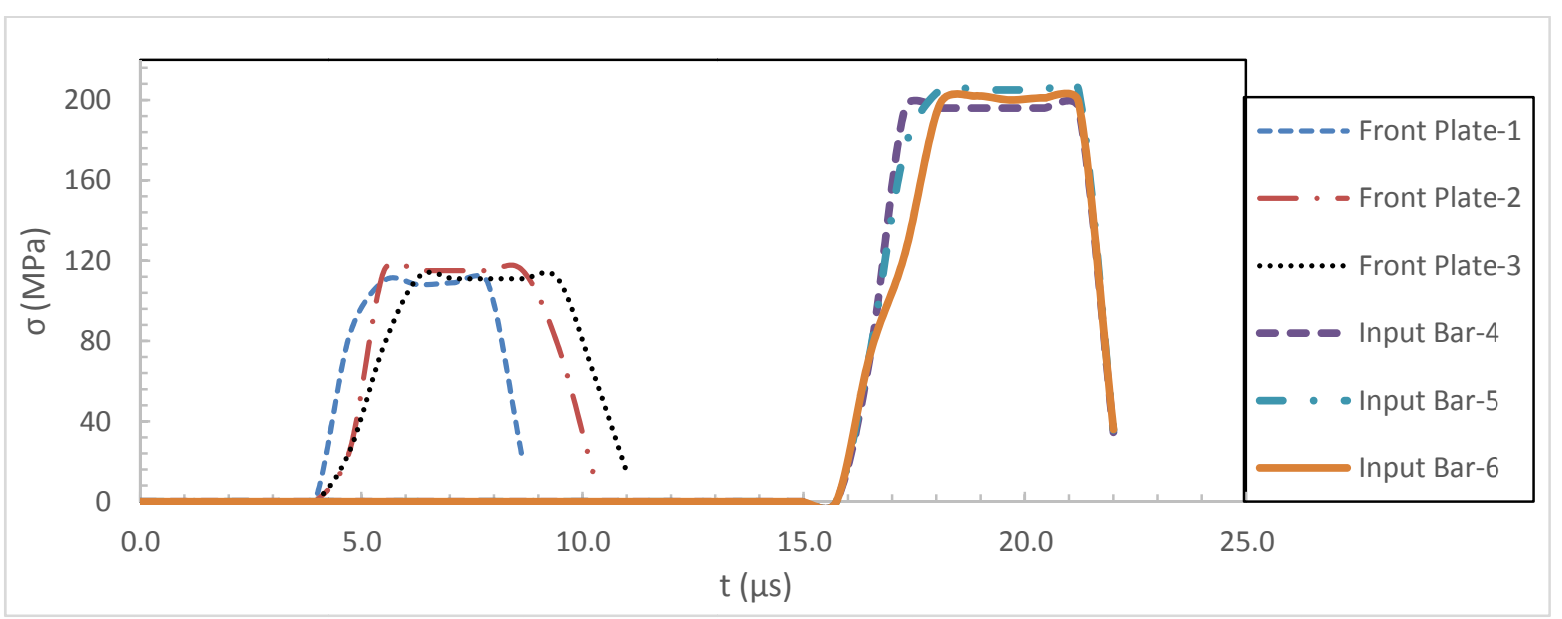

Figure 4. Stress histories for selected elements of front plate and input bar

Furthermore, to verify the reliability of the simulation results, the average maximum stress calculated in two sections using FEM was compared with the theoretical predictions of Equation (10) and Equation (11) (Johnson, 1972), showing differences below $5 \%$.

$$
\begin{gathered}
\sigma_{t}=\frac{2 A_{f} \rho c}{A_{f} \rho_{f} c_{f}+A \rho c} \sigma_{i} \\
\sigma_{r}=\frac{A \rho c-A_{f} \rho_{f} c_{f}}{A_{f} \rho_{f} c_{f}+A \rho c} \sigma_{i}
\end{gathered}
$$

Where $\sigma_{i}, \sigma_{r}$ and $\sigma_{t}$ are incident, reflected and transmitted stresses; $\rho_{f} c_{f}=\rho c$ is the mechanical impedance of steel 4340; $A_{f}$ and $A$ are the front plate and input bar area respectively.

\section{Results and Discussions}

Figure 5 shows the strain history for shot No. 5 achieved by experimental test. Incident strain $\left(\varepsilon_{i}\right)$ and transmitted strain $\left(\varepsilon_{t}\right)$ are acquired by strain gauges mounted on the input and output bars respectively. It appears that some noise recorded by the strain gauge of input bar affects the reflected waves. Therefore, it was decided to calculate the reflected strain $\left(\varepsilon_{r}\right)$ from (Gray, 2000):

$$
\varepsilon_{r}=\varepsilon_{t}-\varepsilon_{i}
$$

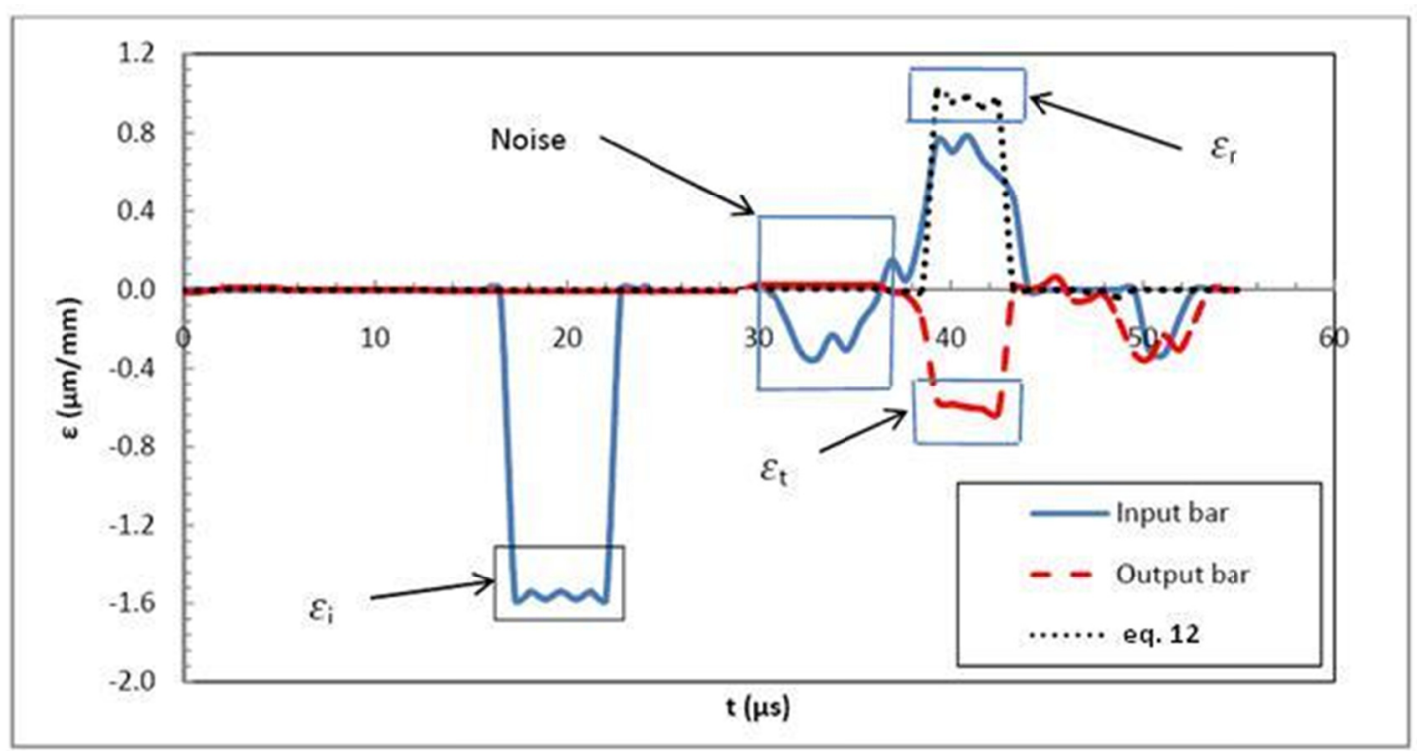

Figure 5. Strain history for Shot No. 5 achieved by experimental test (Incident strain: $\varepsilon_{i}$, transmitted strain: $\varepsilon_{t}$, reflected strain: $\varepsilon_{r}$ ) 
Figure 6 shows the strain history of propagated waves with FEM for shot No. 5. Two elements in the center of the input and output bars were chosen to evaluate the propagation of the pulses along the bars. Considering the comparison between experimental (Figure 4) and numerical results (Figure 5), there are good agreements between them. The rise time differences between Figure 6 and Figure 7 are due to different times of impacting flyers to the front targets.

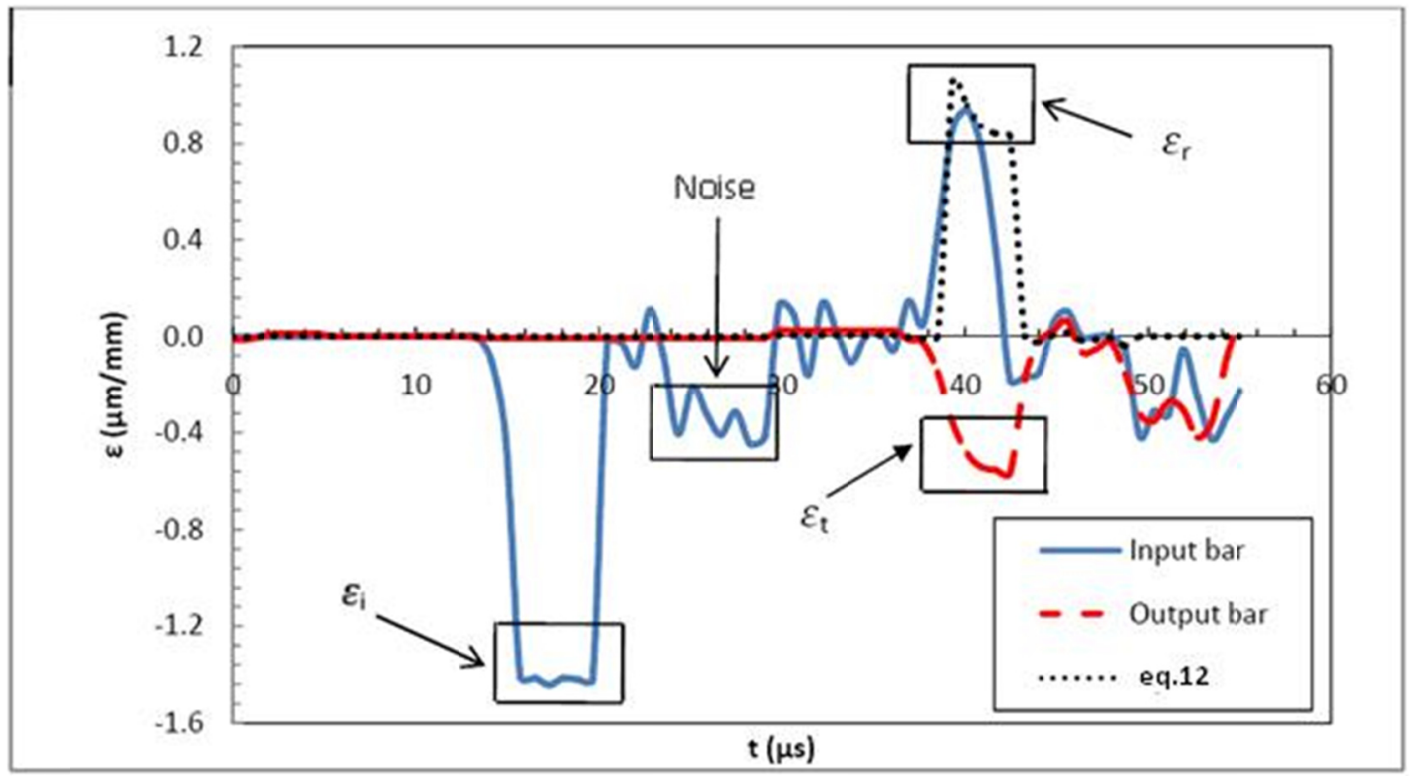

Figure 6. Strain history for Shot No. 5 (numerical simulation)

Considering Figure 5 and 6 for experimental and numerical analysis respectively, strain histories of incident, reflected, and transmitted waves were used to evaluate stress-strain diagrams in the sample. Stress and strain were calculated for both methods from Equation 1 and 3 respectively.

Figure 7 shows the stress-strain diagrams of experimental and numerical results for shot No. 3 and 5 . Table 4 also reports the amounts and error percentages of maximum stresses $\left(\sigma_{\max }\right)$, strains $\left(\varepsilon_{\max }\right)$ and strain rates $\left(\dot{\varepsilon}_{\max }\right)$ in experimental, and numerical analysis for foresaid shots. Considering Figure 7 and Table 4 , good agreement is found between experimental and numerical analysis. Also, Table 5 reports maximum stress, strain and strain rate for different shots achieved by experimental works.

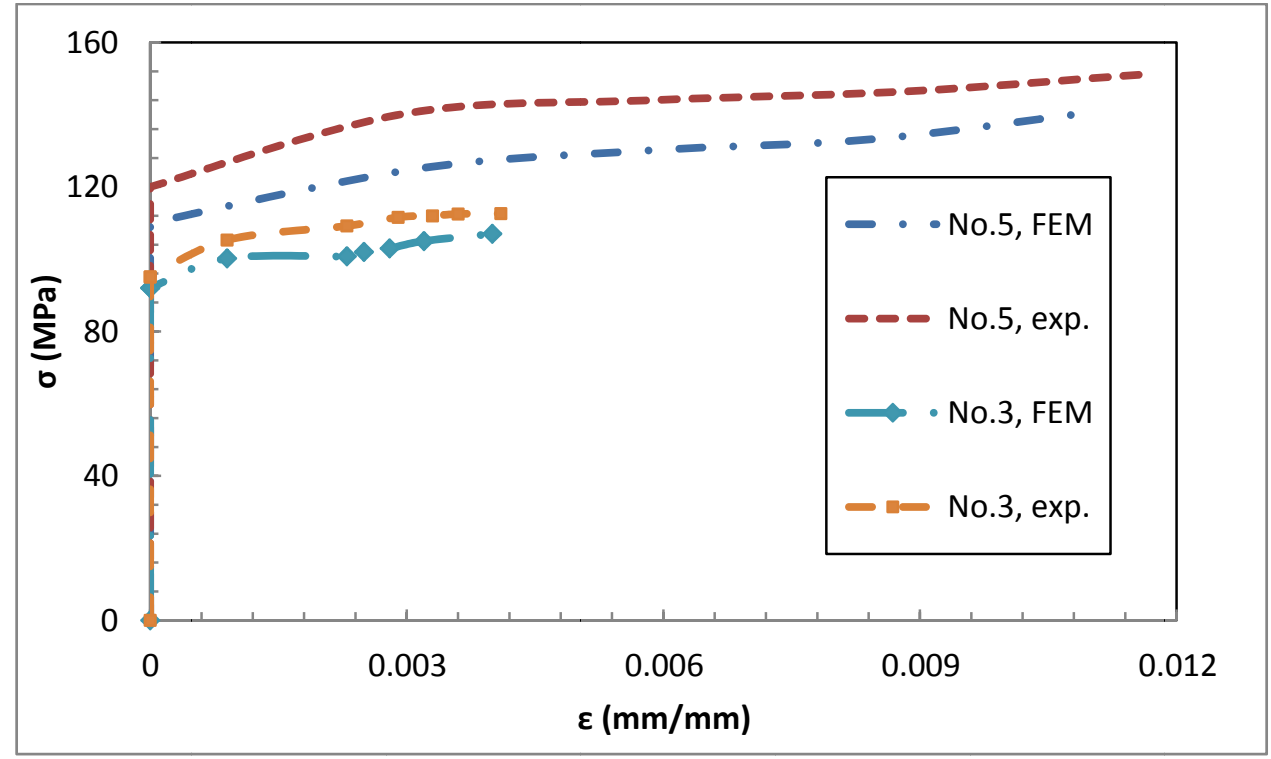

Figure 7. Stress- strain diagrams for shot No. 3 and No. 5 (experiment tests and numerical simulations) 
Table 4. maximum stresses $\left(\sigma_{\max }\right)$, strains $\left(\varepsilon_{\max }\right)$ and strain rates $\left(\dot{\varepsilon}_{\max }\right)$ evaluated with experimental, and numerical analysis for shots No. 3 and 5. Uncertainly is $\pm 5 \mathrm{MPa}$ for $\sigma_{\max }, \pm 5 \times 10^{-4}$ for $\varepsilon_{\max }$ and $\pm 5 \mathrm{~s}^{-1}$ for $\dot{\varepsilon}_{\max }$

\begin{tabular}{cccc}
\hline Shot & $\sigma_{\max }(\mathrm{MPa})$ & $\varepsilon_{\max }$ & $\dot{\varepsilon}_{\max }\left(s^{-1}\right)$ \\
\hline No. 3 (exp.) & 115 & 0.0040 & 805 \\
No. 3 (FEM) & 105 & 0.0040 & 790 \\
$\%$ err. & $8.70 \%$ & $0.00 \%$ & $1.90 \%$ \\
\hline No. 5 (exp.) & 150 & 0.0100 & 3765 \\
No. 5 (FEM) & 140 & 0.0110 & 4135 \\
$\%$ err. & $6.70 \%$ & $10 \%$ & $9.70 \%$ \\
\hline
\end{tabular}

Table 5. Summary of maximum stresses $\left(\sigma_{\max }\right)$, strains $\left(\varepsilon_{\max }\right)$ and strain rates $\left(\dot{\varepsilon}_{\max }\right)$ for different experimental shots. Uncertainly is $\pm 5 \mathrm{MPa}$ for $\sigma_{\max }, \pm 5 \times 10^{-4}$ for $\varepsilon_{\max }$ and $\pm 5 \mathrm{~s}^{-1}$ for $\dot{\varepsilon}_{\max }$

\begin{tabular}{cccc}
\hline Shot & $\sigma_{\max }(M P a)$ & $\varepsilon_{\max }$ & $\dot{\varepsilon}_{\max }\left(s^{-1}\right)$ \\
\hline 1 & 125 & 0.0055 & 1060 \\
2 & 135 & 0.0070 & 2120 \\
3 & 115 & 0.0040 & 803 \\
4 & 100 & 0.0025 & 200 \\
5 & 150 & 0.0100 & 3765 \\
6 & 155 & 0.0120 & 4260 \\
\hline
\end{tabular}

Figure 8 shows the effect of projectile velocity on stress-strain plots by measuring the experimental results obtained in tests No. 1, 2, 5 and 6. It's appears that increasing flyer velocity, results in increasing stress and strain rate.

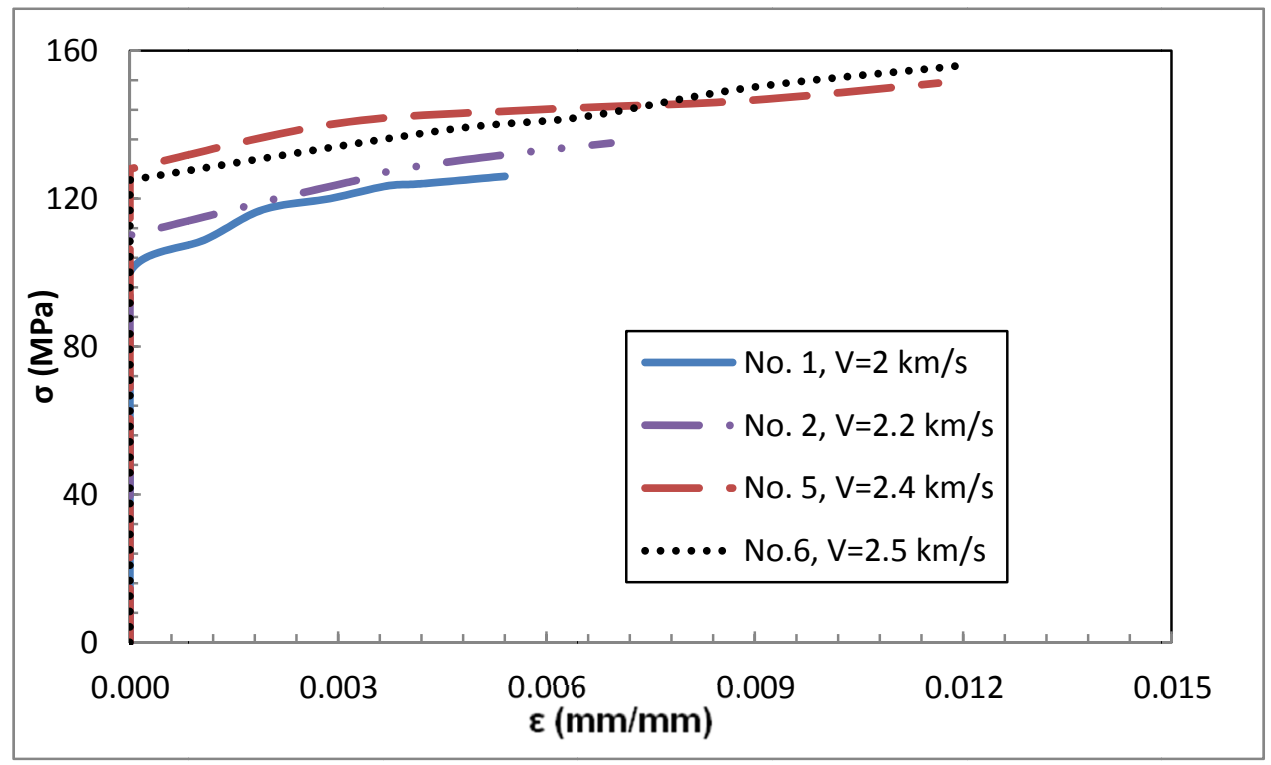

Figure 8. Effect of projectile velocity in stress-strain plot

However, there are limitations to increase flyer velocity to achieve higher strain rates because, according to numerical simulation and under impacting Al 1100 flyer to steel 4340 front plate maximum flyer velocity should be $3 \mathrm{~km} / \mathrm{s}$ respectively to achieve plane waves in input bar. 
Figure 9 depicts the stress-strain diagram evaluating the effect of OFHC copper thickness $\left(\mathrm{h}_{\mathrm{s}}\right)$ for shots No. 1, 3 and 4. Note that all the parameters except sample thickness remain constant. Considering Figure 9 and Table 5, with increasing sample thickness, stress, strain and strain rate decrease.

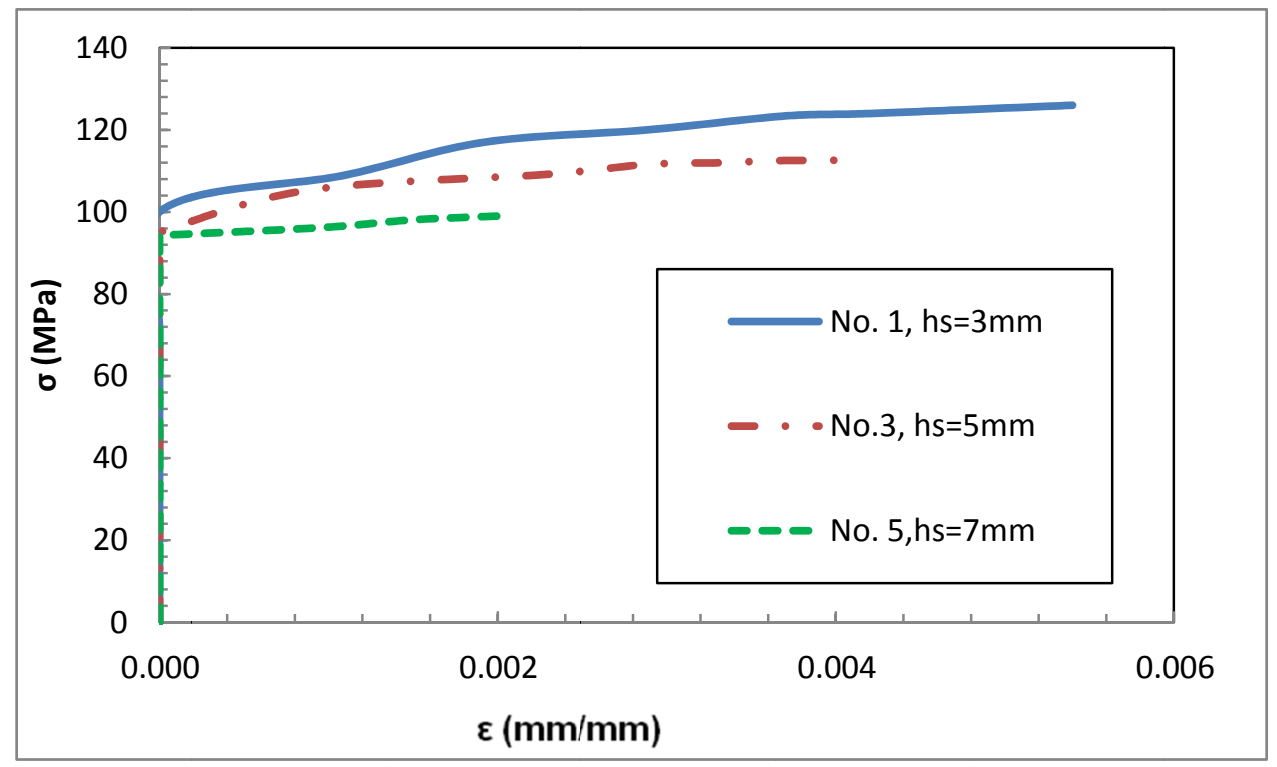

Figure 9. Effect of specimen thicknesses in stress-strain plot

\section{Conclusions}

This paper has presented a new method to investigate plastic deformation of OFHC copper in high strain rate loadings. The method is similar to Split Hopkinson Pressure bar, except that the striker bar is eliminated and a spherical aluminum projectile is used to impact with high velocity to a front steel plate attached to the input bar.

The diameter of aluminum spherical projectile is $3.5 \mathrm{~mm}$ and projectile velocity changes from 2 to $2.5 \mathrm{~km} / \mathrm{s}$. The sample is OFHC copper with the diameter of $5 \mathrm{~mm}$ and different thicknesses of 3-7 mm. This new method has the ability to create high strain rates between 200 and $4260 \mathrm{~s}^{-1}$ in OFHC copper. Results show that with decreasing sample thickness and increasing projectile velocity, strain rate increases.

The experimental results have been verified with $3 \mathrm{D}$ finite element simulation. There has been a good agreement between the experimental and numerical results.

\section{Acknowledgement}

The authors appreciate technicians of the gas gun facility, University of Padova, Mr. Luca Tasinato, Mr. Gabriele Masiero, Mr. Filippo Dona and Mr. Francesco Babolin for their efforts to prepare the set-up and run the tests.

\section{References}

Angrilli, F., Pavarin, D., De Cecco, M., \& Francesconi, A. (2003). Impact facility based upon high frequency two-stage light-gas gun. Acta Astronautica, http://dx.doi.org/10.1016/S0094-5765(02)00207-2

Armstrong, R. W., \& Walley, S. M. (2008). High strain rate properties of metals and alloys. International Materials Reviews, 53(3), 105-128. http://dx.doi.org/10.1179/174328008X277795

Clausen, A. H., Børvik, T., Hopperstad, O. S., \& Benallal, A. (2004). Flow and fracture characteristics of aluminium alloy AA5083-H116 as function of strain rate, temperature and triaxiality. Materials Science and Engineering: A, 364(1), 260-272. http://dx.doi.org/10.1016/j.msea.2003.08.027

Colombo, P., Arcaro, A., Francesconi, A., Pavarin, D., Rondini, D., \& Debei, S. (2003). Effect of hypervelocity impact on microcellular ceramic foams from a preceramic polymer. Advanced Engineering Materials, 5(11), 802-805. http://dx.doi.org/10.1002/adem.200300397 
Corbett, B. M. (2006). Numerical simulations of target hole diameters for hypervelocity impacts into elevated and room temperature bumpers. International Journal of Impact Engineering, 33(1), 431-440. http://dx.doi.org/10.1016/j.ijimpeng.2006.09.086

Fathipour, M., Zoghipour, P., Tarighi, J., \& Yousefi, R. (2012). Yousefi R, Investigation of Reinforced Sic Particles Percentage on Machining Force of Metal Matrix Composite. Modern Applied Science, 6(8), 9-20. http://dx.doi.org/10.5539/mas.v6n8p9

Field, J. E., Walley, S. M., Proud, W. G., Goldrein, H. T., \& Siviour, S. R. (2004). Review of experimental techniques for high rate deformation and shock studies. International J of Impact Engineering, 30, 725-775 http://dx.doi.org/10.1016/j.ijimpeng.2004.03.005.

Follansbee, P. S., \& Gray III, G. T. (1991). Dynamic deformation of shock prestrained copper. Materials Science and Engineering: A, 138(1), 23-31. http://dx.doi.org/10.1016/0921-5093(91)90673-B

Follansbee, P. S., \& Kocks, U. F. (1988). A constitutive description of the deformation of copper based on the use of the mechanical threshold stress as an internal state variable. Acta Metallurgica, 36, 81-93. http://dx.doi.org/10.1016/0001-6160(88)90030-2

Francesconi, A., Giacomuzzo, C., Barilaro, L., Segato, E., \& Sansone, F. (2013). Experimental Study of Spacecraft material ejected upon hypervelocity impact. In Proc. $6^{\text {th }}$ Europ. Conf. on Space Debris, 22-25 April, ESA SP-923, Darmstadt, Germany.

Francesconi, A., Giacomuzzo, C., Branz, F., \& Lorenzini, F. (2013). Survivabiity to hypervelocity impacts of electrodynamic tape tethers for deorbiting spacecraft in LEO. In Proc. $6^{\text {th }}$ Europ. Conf. on Space Debries, 22-25 April, ESA SP-923, Darmstadt, Germany.

Francesconi, A., Giacomuzzo, C., Grande, A. M., Mudric, T., Zaccariotto, M., Etemadi, E., ... Galvanetto, U. (2013). Comparison of self-healing ionomer to aluminium-alloy bumpers for protecting spacecraft equipment from space debris impacts. Advances in Space Research, 51(5), 930-940. http://dx.doi.org/10.1016/j.asr.2012.10.013

Francesconi, A., Giacomuzzo, C., Kibe, S., Nagao, Y., \& Higashide, M. (2012). Effects of high-speed impacts on CFRP plates for space applications. Advances in Space Research, 50(5), 539-548. http://dx.doi.org/10.1016/j.asr.2012.05.012

Francesconi, A., Pavarin, D., Bettella, A., \& Angrilli, F. (2008). A special design condition to increase the performance of two-stage light-gas guns. International Journal of Impact Engineering, 35(12), 1510-1515. http://dx.doi.org/10.1016/j.ijimpeng.2008.07.035

Francesconi, A., Pavarin, D., Bettella, A., Giacomuzzo, C., Faraud, M., Destefanis, R., ... Angrilli, F. (2008). Generation of transient vibrations on aluminum honeycomb sandwich panels subjected to hypervelocity impacts. International Journal of Impact Engineering, 35(12), 1503-1509. http://dx.doi.org/10.1016/j.ijimpeng.2008.07.034

Francesconi, A., Pavarin, D., Giacomuzzo, C., \& Angrilli, F. (2006). Impact experiments on low-temperature bumpers. International Journal of Impact Engineering, 33(1), $264-272$. http://dx.doi.org/10.1016/j.ijimpeng.2006.09.056

Frutschy, K. J., \& Clifton, R. J. (1998). High-temperature pressure-shear plate impact experiments on OFHC copper. Journal of the Mechanics and Physics of Solids, 46(10), 1723-1744. http://dx.doi.org/10.1016/S0022-5096(98)00055-6

Gerlach, R., Kettenbeil, C., \& Petrinic, N. (2012). A new split Hopkinson tensile bar design. International Journal of Impact Engineering, 50, 63-67. http://dx.doi.org/10.1016/j.ijimpeng.2012.08.004

Gilat, A., \& Cheng, C. S. (2002). Modeling torsional split Hopkinson bar tests at strain rates above 10,000 s ${ }^{-1}$. International Journal of Plasticity, 18(5), 787-799. http://dx.doi.org/10.1016/S0749-6419(01)00055-9

Gray, G. T. (2000). Classic split-Hopkinson pressure bar testing. In H. Kuhn \& D. Medlin (Eds.), ASM handbook. Mechanical testing and evaluation (vol. 8, p. 462e76). Ohio: ASM International: Materials Park.

Higeshide, M., Nagao, Y., KIbe, S., Francesconi, A., \& Pavarin, D. (2009). Ballistic limit of thin CFRP plates. In Proc. $5^{\text {th }}$ Europ. Conf. on space Debries, 30 March-2 April, ESA SP-672, Darmstadt, Germany,.

Johnson, G. R., \& Cook, W. H. (1983). A constitutive model and data for metals subjected to large strains, high strain rates, and high temperatures. In 7th Int. Symp. on 'Ballistics', The Hague, The Netherlands 1983 (pp. 541-547). American defense preparedness association. 
Johnson, G. R., \& Cook, W. H. (1985). Fracture characteristics of three metals subjected to various strains, strain rates, temperatures and pressures. Engineering Fracture Mechanics, 21(1), 31-48. http://dx.doi.org/10.1016/0013-7944(85)90052-9

Johnson, W. (1972). Impact Strength of Materials (1st ed.). Edward Arnold.

Kajberg, J., \& Sundin, K. (2013). Material characterization using high-temperature Split Hopkinson pressure bar . $\begin{array}{lllll}\text { Journal of Materials Processing } & \text { Technology, 213, }\end{array}$ http://dx.doi.org/10.1016/j.jmatprotec.2012.11.008

Kajberg, J., \& Wikman, B. (2007). Viscoplastic parameter estimation by high strain-rate experiments and inverse modelling-Speckle measurements and high-speed photography. International Journal of Solids and Structures, 44(1), 145-164. http://dx.doi.org/10.1016/j.ijsolstr.2006.04.018

Kapoor, R., \& Nemat-Nasser, S. (1998). Determination of temperature rise during high strain rate deformation. Mechanics of Materials, 27(1), 1-12. http://dx.doi.org/10.1016/S0167-6636(97)00036-7

Khosravifard, A., Moshksar, M. M., \& Ebrahimi, R. (2013). High strain rate torsional testing of a high manganese steel: Design and simulation. Materials \& Design, 52, 495-503. http://dx.doi.org/10.1016/j.matdes.2013.05.083

Li, Y., \& Ramesh, K. T. (2007). An optical technique for measurement of material properties in the tension Kolsky bar. International Journal of Impact Engineering, 34(4), 784-798. http://dx.doi.org/10.1016/j.ijimpeng.2005.12.002

Liang, R., \& Khan, A. S. (1999). A critical review of experimental results and constitutive models for BCC and FCC metals over a wide range of strain rates and temperatures. International Journal of Plasticity, 15(9), 963-980. http://dx.doi.org/10.1016/S0749-6419(99)00021-2

Liu, X., Tan, C., Zhang, J., Hu, Y., Ma, H., Wang, F., \& Cai, H. (2009). Influence of microstructure and strain rate on adiabatic shearing behavior in Ti-6Al-4V alloys. Materials Science and Engineering: A, 501, 30-36. http://dx.doi.org/10.1016/j.msea.2008.09.076

Liu, Y. J., \& Sun, Q. (2014). A dynamic ductile fracture model on the effects of pressure, Lode angle and strain rate. Materials Science and Engineering: A, 589, 262-270. http://dx.doi.org/10.1016/j.msea.2013.09.082

Meyers, M. A. (1994). Dynamic behavior of Materials (1st ed.). Wiley. http://dx.doi.org/10.1002/9780470172278

Nagao, Y., Kibe, S., Daigo, K., Francesconi, A., \& Pavarin, D. (2005). Hypervelocity impact studies simulating debris collision on composites material (Proceedings of the 4th European Conference on Space Debris (ESA SP-587), p.413. 18-20 April 2005, ESA/ESOC, Darmstadt, Germany.

Pavarin, D., \& Francesconi, A. (2003). Improvement of the CISAS high-shot-frequency light-gas gun. $\begin{array}{lllll}\text { International Journal of Impact } & \text { Engineering, }\end{array}$ http://dx.doi.org/10.1016/j.ijimpeng.2003.10.004

Pavarin, D., Francesconi, A., Destefanis, R., Faraud, M., Lambert, M., Bettella, A., ... \& Angrilli, F. (2008). Analysis of transient vibrations on complex targets representing elementary configurations of GOCE satellite. International Journal of Impact Engineering, 35(12), 1709-1715. http://dx.doi.org/10.1016/j.ijimpeng.2008.07.014

Qin, J., Chen, R., Wen, X., Lin, Y., Liang, M., \& Lu, F. (2013). Mechanical behaviour of dual-phase high-strength steel under high strain rate tensile loading. Materials Science and Engineering: A, 586, 62-70. http://dx.doi.org/10.1016/j.msea.2013.07.091

Ravichandran, G., \& Subhash, G. (1994). Critical appraisal of limiting strain rates for compression testing of ceramics in a split Hopkinson pressure bar. Journal of the American Ceramic Society, 77(1), 263-267. http://dx.doi.org/10.1111/j.1151-2916.1994.tb06987.x

Ren, X. D., Zhan, Q. B., Yang, H. M., Dai, F. Z., Cui, C. Y., Sun, G. F., \& Ruan, L. (2013). The effects of residual stress on fatigue behavior and crack propagation from laser shock processing-worked hole. Materials \& Design, 44, 149-154. http://dx.doi.org/10.1016/j.matdes.2012.07.024

Sasso, M., Newaz, G., \& Amodio, D. (2008). Material characterization at high strain rate by Hopkinson bar tests and finite element optimization. Materials Science and Engineering: A, 487, 289-300. http://dx.doi.org/10.1016/j.msea.2007.10.042 
Sedighi, M., Khandaei, M., \& Shokrollahi, H. (2010). An approach in parametric identification of high strain rate constitutive model using Hopkinson pressure bar test results. Materials Science and Engineering: A, 527(15), 3521-3528. http://dx.doi.org/10.1016/j.msea.2010.02.025

Steinberg, D. J. (1996). Equation of state and strength properties of selected materials (1st ed.). Lawrence Livermore National Laboratories.

Verleysen, P., \& Degrieck, J. (2006, August). Experimental and numerical study of the response of steel sheet Hopkinson specimens. In Journal de Physique IV (Proceedings) (Vol. 134, pp. 541-546). EDP sciences.

Wang, Z. G., \& Meyer, L. W. (2010). On the plastic wave propagation along the specimen length in SHPB test. Experimental mechanics, 50(7), 1061-1074. http://dx.doi.org/10.1007/s11340-009-9294-x

Yang, B., Tang, L., Liu, Y., Liu, Z., Jiang, Z., \& Fang, D. (2013). Localized deformation in aluminium foam during middle speed Hopkinson bar impact tests. Materials Science and Engineering: A, 560, 734-743. http://dx.doi.org/10.1016/j.msea.2012.10.027

Yang, L. M., \& Shim, V. P. W. (2005). An analysis of stress uniformity in split Hopkinson bar test specimens. $\begin{array}{llll}\text { International Journal of Impact Engineering, } & 31(2), & 129-150 .\end{array}$ http://dx.doi.org/10.1016/j.ijimpeng.2003.09.002

Zou, D. L., Luan, B. F., Liu, Q., Chai, L. J., \& Chen, J. W. (2012). Characterization of adiabatic shear bands in the zirconium alloy impacted by split Hopkinson pressure bar at a strain rate of $6000 \mathrm{~s}^{-1}$. Materials Science and Engineering: A, 558, 517-524. http://dx.doi.org/10.1016/j.msea.2012.08.038

\section{Copyrights}

Copyright for this article is retained by the author(s), with first publication rights granted to the journal.

This is an open-access article distributed under the terms and conditions of the Creative Commons Attribution license (http://creativecommons.org/licenses/by/3.0/). 